Гусарова Марина Александровна

доктор философских наук, кандидат социологических наук, доцент, доцент кафедры общетеоретических правовых дисциплин Северо-Кавказского филиала Российского государственного университета правосудия

\section{К ВОПРОСУ ОБ ИСТОКАХ ИНТЕГРАТИВНОГО ПРАВОПОНИМАНИЯ В ТРУДАХ П.А. СОРОКИНА, А.С. ЯЩЕНКО, П.Г. ВИНОГРАДОВА}

\section{Аннотация:}

Статья посвящена формированию интегративного (синтетического) типа правопонимания в дореволюционной теории права и философии права. Автором рассматриваются идеи выдающихся отечественных ученых дореволюционного периода - П.А. Сорокина, А.С. Ященко, П.Г. Виноградова - о праве как особой нормативной знаковосимволической и институциональной системе, выступающей неотъемлемой частью общей системы социального регулирования. В работе показаны основные способы преодоления крайностей традиционных подходов к праву (ecmeственно-правового, позитивистского, социологического), представленные в трудах указанных мыслителей. Делается вывод о значимости в современных условиях развития российского общества идей системности права, включения в круг источников права наряду с законом комплекса естественных прав, норм обычного права и правового сознания, а также актуализации государственно-правовых институций в процессе социального реформирования.

\section{Ключевые слова:}

право, правопонимание, интегральная юриспруденция, синтетический подход, социально-правовая реальность, правосознание, система права, нормативность, естественное право, позитивное право.

\section{Gusarova Marina Aleksandrovna}

\author{
D.Phil., PhD in Social Science, \\ Associate Professor, General \\ Theoretical and Legal Department, \\ North Caucasus branch of Russian \\ State University of Justice
}

\section{ON THE ORIGINS OF \\ INTEGRATIVE LEGAL THINKING IN THE WORKS OF P.A. SOROKIN, A.S. YASHCHENKO, AND P.G. VINOGRADOV}

Summary:

The paper deals with an integrative (synthetic) type of legal thinking in the pre-revolutionary theory of law and philosophy of law. The author examines the ideas of P.A. Sorokin, A.S. Yashchenko, and P.G. Vinogradov, the outstanding Russian legal scientists of the prerevolutionary period, about the law as a special normative symbolic and institutional system, which is an integral part of the common system of social regulation. The research shows the main ways to overcome the extremes of traditional approaches to law (natural law, positivist, sociological ones) as represented in the works of these thinkers. The author concludes that it is important to develop the ideas about the system-based law in modern Russian society, include a set of natural laws, standards of customary law and legal thinking along with legislation in the sources of law, and update state legal institutions during social reforms.

Keywords: law, legal thinking, integrative jurisprudence, synthetic approach, social and legal reality, sense of justice, system of law, normativity, natural law, positive law.

Принцип интегративности, или синтетичности, привлекает пристальное внимание современных филлософов, правоведов и социологов, набирая все большую популярность при рассмотрении политико-правовых феноменов в условиях глобализации и усложняющейся социальноправовой реальности. В.В. Ершов справедливо отмечает, что влияние глобализационных фракторов сегодня уже нельзя считать только социальной, экономической или политической проблемой, оно является также правовой проблемой, что подтверждается тесным взаимодействием международного и внутригосударственного права [1, с. 12-14]. Вместе с тем необходимость для Российского государства защищать собственную позицию на международной арене с помощью правовых средств выступает еще одним аргументом в пользу конструирования обновленной теории права, адекватной вызовам современности. Несмотря на это, вопрос понимания права в отечественной традиции неоднократно рассматривался современными авторами (например, В.Г.Графским, В.В. Ершовым, Р.Р. Палехой, В.Н. Корневым, Г.Ф. Гараевой, А.В. Поляковым и др.). Значимость разработки интегративного (синтетического) подхода к праву в качестве обновленной методологии, позволяющей познать действующую правовую реальность на новом уровне, доказывает необходимость ревизии теоретических достижений отечественных исследователей в этой области знаний и актуализации некоторых из их идей. 
Нужно отметить, что в западной общественно-правовой мысли XX - начала XXI в. данный подход, разработанный такими авторами, как Л. Фуллер, Дж. Холл и Г.Дж. Берман, вошел в научный оборот в середине XX в. под названием «интегративный», или «интегральный», он предполагал внутренне непротиворечивый синтез естественно-правового и позитивистского типов правопонимания [2]. Однако отечественной дореволюционной правовой теории и философрии права начала XX в. уже был достаточно известен так называемый «синтетический» подход к праву, разработанный независимо друг от друга выдающимися российскими учеными - П.А. Сорокиным, А.С. Ященко, П.Г. Виноградовым и др., которые представили новаторскую для своего времени методику исследования права как сложноструктурированной нормативной системы социума, преломляющейся посредством правосознания и идентифицирущейся в форме идеальных правовых конструкций, правовых психологических феноменов и правового поведения. Идейными основаниями для первых синтетических теорий права в России, по мнению современных авторов, выступали концепции К.А. Неволина, Б.Н. Чичерина, В.Г. Щеглова и др., в трудах которых уже прослеживалась возможность примирения естественного и позитивного права [3, с. 38-39].

Необходимо отметить, что разноплановые интегративные концепции П.А. Сорокина, А.С. Ященко, П.Г. Виноградова, содержание которых рассматривается в данной статье, можно подвести под общий знаменатель: все три автора строят рассуждения о феномене права, начиная с выявления его места в классификации социальных явлений и раскрытия его родовидовых признаков, завершая исследования оригинальной авторской формулировкой определения права, вмещающего в себя разнообразные собственно правовые и исторически сопутствующие феномены. Например, П.Г. Виноградов писал, что право относится к кругу социальных явлений, имеющих, наряду с модой, моралью, обычаями, нормативно-регулятивный, коммуникативный и социально-стабилизирующий характер. Уникальная позиция правовых норм «между правилами поведения, которые обеспечивают социальный порядок и социальное общение», по мнению ученого, позволяет отнести науку о праве «к разряду так называемых моральных наук» [4, с. 10], что еще раз подтверждает фракт исторически обусловленного переплетения правовых и морально-этических элементов в традиционном российском правовом сознании.

Русско-американский социолог и культуролог П.А. Сорокин в одной из ранних работ также относит право к разряду социальных явлений, в котором выделяет две неотрывные друг от друга стороны: внутреннепсихическую и внешнесимволическую [5]. Данное положение объясняет тот фракт, что учение о праве, представленное в трудах П.А. Сорокина, тесно переплетено с объяснением особенностей функционирования механизма социального регулирования в целом и правового регулирования как его неотъемлемой части. При этом правовая норма в интегративной концепции П.А. Сорокина выступает центрообразующим звеном правового института, а социальное поведение индивидов и групп - способом объективации права в социальной реальности.

П.А. Сорокин, конструируя определение права как правила поведения, основывающегося на долженствовании, дозволениях и запретах, акцентирует внимание на внутреннем содержании права, апеллирующем посредством сформировавшихся «кар» и «наград» к правосознанию субъекта. Очевидно, что ученый симпатизировал психологической теории права Л. Петражицкого, используя такие термины для объяснения субъективных реакций на право, как «правовая боль», «правовое чувство», «морально-правовой термометр» и др. [6, с. 10]. Описывая многообразие сущностных особенностей права, реализующихся в его функциональном назначении, П.А. Сорокин называет его «чистой мотивирующей силой, способствующей формированию гражданина» [7, с. 176], а также «принудительной» и «дрессирующей силой» [8, с. 182, 185]. Важно отметить, что П.А. Сорокин в отличие от его современников П.Г. Виноградова и А.С. Ященко не ставил перед собой задачу построить самостоятельную правовую концепцию, поскольку не считал право изолированным от социальной реальности явлением, но объяснял его как совокупность разнообразных знаково-символических и институциональных элементов, что позволяет отнести его учение к числу тех, благодаря которым происходил генезис интегративного подхода к праву в отечественной правовой мысли.

В противоположность позиции правоведов, представителей позитивистского направления (например, Дж. Остина, Г. Кельзена и др.), которые определяют право как совокупность норм принудительного характера, установленных и поддерживаемых государственным аппаратом, П.Г. Виноградов доказывает, что только принятые и одобренные правовым сознанием субъекта нормы позитивного права будут исполняться осмысленно. При этом за скобками правовой ответственности остаются сами творцы норм. П.Г. Виноградов справедливо отмечает: «если сущностью закона является принуждение, то закон обязателен для подданных и подчиненных, высшие же лица государства стоят над законом и вне его. Но в таком случае, почему же общественное мнение так резко противопоставляет право силе?» [9, с. 23]. Ученый категорично заявляет, что сила правовых норм «зависит от их признания» [10, с. 24]. Согласно П.Г. Виноградову, 
особняком от остальных норм стоят нормы международного права, имеющие в основном рекомендательный характер, обусловленный его естественно-правовым содержанием и живой связью с конституционным правом.

Несомненной заслугой П.Г. Виноградова в попытке обоснования права как системы является выстраивание иерархии источников права. Так, по значимости в системе права он располагает естественное право, законодательство, право, выработанное судьями, и обычное право. Каждый из названных источников не может служить в качестве самодостаточного, он значим только в соотношении с остальными. Рассматривая генезис естественного права в обществе, П.Г. Виноградов приходит к выводу, что «содержание естественного права меняется вместе с эпохами, но цель его остается постоянной, и эта цель - справедливость» [11, с. 151-152].

Что касается обычного права или юридических обычаев, то в унисон с Ф. Савиньи и другими представителями исторической школы П.Г. Виноградов подчеркивал значимость данного источника права, обусловленную его глубинными связями со скрытыми в правовой ментальности народа принципами, которые «в большей степени совпадают с понятиями о справедливости, свойственными данному обществу, чем искусственные создания государственной власти или научной юриспруденции» [12, с. 93]. Следовательно, обычай как источник права гарантирует адекватность реальным правовым ситуациям и правовой психологии народа.

Независимо от П.А Сорокина и П.Г. Виноградова А.С. Ященко также использовал аналогичный алгоритм исследования сущности права, начиная с анализа его классовых, родовых и видовых признаков. Объясняя возникновение синтетической теории права в современной ему науке, А.С. Ященко отмечает, что каждая новая социальная система порождает новые теории, которые вытесняют и уничтожают друг друга, таким образом, движение научного знания превращается в тщетный сизифов труд, приводящий к «внешнему эклектизму». Собственный подход А.С. Ященко представляет как «соединение всех односторонних определений на основании синтезирующей силы всеобъемлющего начала, являющегося живой душой всего соединения» [13, с. 9]. Данную методологию он применяет и к целому - обществу, и к его части - праву, что, очевидно, роднит его теорию с концепцией П.А. Сорокина. Согласно А.С. Ященко, в самом широком смысле право может быть определено как совокупность правил поведения людей в обществе, а общество - как коллективно-психологическое явление, органическая личностно-общественная двусторонность которого выступает «последствием своеобразного психологического синтеза» [14, с. 2]. Солидаризируясь с мнением современных авторов, подчеркнем, что построение обозначенной дефиниции права было возможно благодаря сильнейшему влиянию на А.С. Ященко идей Вл. Соловьева о равновесии личного и общего интересов, индивидуальной свободы и общественного блага. Последние были положены в качестве философского принципа - основания для творчески переработанной правовой концепции А.С. Ященко [15, с. 84-86].

Выявляя недостатки юснатуралистического подхода И. Канта, искавшего критерии нравственной правильности не в правовых фактах, а внутри познающего субъекта, тем самым отстаивая идею внутренней самозаконности нравственности, А.С. Ященко заявляет, что Кант просчитался, «лишив высший принцип нравственности всякого эмпирического и психологического содержания» [16, с. 43]. По мнению ученого, принцип воли также не может быть обусловлен внутренним состоянием субъекта, но «берется из эмпирического мира, в применении к эмпирической воле. Идея воздействия закона на волю говорит нам об эмпирическом законе причинности» [17, с. 45].

Определяя природу естественного права, А.С. Ященко акцентирует внимание на нравственном принципе как основе естественного права. Данный принцип, согласно мнению ученого, «не зависит ни от какого случайного, внешнего и формального признака, он вытекает из разума и нравственного сознания людей; он не подлежит отмене, а лишь углублению; он определяет собою и право положительное, и власть, и в случае конфликтов между нравственным сознанием и формально-юридическими нормами последнее слово должно остаться за нравственным сознанием. Это нравственное сознание и есть естественное право» [18, с. 91-92]. Вместе с тем в споре с отечественными юснатуралистами - П.И. Новгородцевым, Е.Н. Трубецким и др. - А.С. Ященко подвергает критике утверждение, что естественно-правовые нормы обязательны для государства. Причину возникших разночтений мыслитель видит в дуализме нравственных норм, которые могут одновременно как существовать в качестве субъективно значимых, так и быть объективно значимыми, находящимися вне времени. В связи с этим наиболее образцовой из западноевропейских юснатуралистических теорий А.С. Ященко признавал концепцию Л. Дюги, согласно которой «разумна и оправданна только та система положительных законов, которая построена на уважении к праву, общественной солидарности» [19, с. 104].

Следует обратить внимание на тот факт, что А.С. Ященко еще не использовал термин «правосознание», поскольку его широкое употребление в общественно- и теоретико-правовой 
литературе в аспекте кризисного состояния приходится на первую четверть XX в. благодаря работам преимущественно представителей естественно-правового подхода - И.А. Ильина, Б.А. Кистяковского, П.И. Новгородцева и др. [20], однако в упомянутом суждении речь идет именно о правосознании как результате рефлексивной познавательно-оценочной деятельности правового субъекта относительно правовой реальности, основанной на процессах интериоризации и экстериоризации. Как представляется, объясняя феномен дуализма нравственных норм, A.C. Ященко, сам того не подозревая, затронул весьма важную проблему активности правового сознания, которой не остается места в традиционных позитивистских теориях правопонимания и которая «растворяется» в естественно-правовых теориях. Лишь синтетическая методология познания права способна примирить идею естественного права как важного источника права без принудительного элиминирования из нее институциональной, рационально-практической ипостаси права, демонстрирующей реализацию норм естественного права в действительности.

Нетрудно заметить, что дуализм естественного и положительного права, ставший опорным моментом в размышлениях современников А.С. Ященко, признается тупиковым путем в проблеме понимания сущности права, главная идея которого, по мнению ученого, заключается «в установлении должного равновесия между стремлением к личной свободе и общим благом (это и есть справедливость)... Для того чтобы общая идея права (естественное право, в нашем смысле слова) могла послужить основанием действительно правовой критики, необходимо, чтобы эта идея права получалась, извлекалась из рассмотрения исторически действующего юридического материала» [21, с. 111]. Важно отметить, что А.С. Ященко указал на весьма важную проблему, остающуюся актуальной и в наши дни. Речь идет о комплексе рефлексивных и креативных свойств правового сознания, позволяющих индивидуальным и коллективным правовым инструментам извлекать жизнеспособные, приемлемые для правовой психологии идеи и механизмы правового регулирования из истории права и институтов того или иного народа.

Примечательно, что в психологической теории права своего современника - Л.И. Петражицкого - А.С. Ященко также обнаруживает некоторые противоречия. Допуская, что право является психологическим феноменом и порождает правовые эмоции, переживания, чувства в участниках правоотношений, он подчеркивает наличие коллективно-психологического характера права, порожденного социальностью как таковой. «Интуитивное право», которое Л.И. Петражицкий назвал правом вообще, согласно А.С. Ященко, «есть то обычное право, которое часто расходится с законом. Оно приближается к нравственности» [22, с. 108], в нем отмечаются не переживания отдельных лиц, а совпадение переживаний сторон, что еще раз подтверждает коллективно-психологический характер права. Резюмируя свои размышления о праве, А.С. Ященко констатирует, что «право не только живет в психическом мире отдельных людей, но и отлагается в объективных институтах, запечатлевается в юридических памятниках, с неизменною правильностью применяется в субъективных решениях, в обычаях, в законах, слагается в сложные и многообразные установления» [23, с. 181].

Таким образом, право в теории А.С. Ященко предстает как явление коллективно-психического характера, совокупность норм поведения, устанавливающих равновесие между личными и общественно значимыми интересами в результате личной активности и принудительных действий органов власти. Нельзя не отметить, что, как и у П.Г. Виноградова, в концепции А.C. Ященко в латентной форме (без упоминания термина) присутствует феномен правосознания, который выступает неотъемлемым элементом системы социально-правового регулирования, приводя в движение объективно значимое и субъективно значимое, идею права и реальные правовые нормы, т. е. должное и сущее. «Примирение» естественного и позитивного права в качестве граней одного и того же явления - права - позволяет, по мнению В.Н. Жукова, отнести теорию А.С. Ященко к правовым монистическим концепциям [24, с. 104].

Подытоживая сказанное, следует отметить, что особенность синтетического подхода к праву, развитого в трудах П.Г. Виноградова, А.С. Ященко и П.А. Сорокина, заключается не в механическом аккумулировании преимуществ традиционных подходов к праву, он позволяет дать оценку и анализ права с системной точки зрения, т. е. рассмотреть его как феномен, обладающий одновременно и духовной, и материальной природой, а следовательно, предполагающий диалектическое взаимодействие всех элементов социальной нормативной системы. Несомненной заслугой упомянутых авторов выступают, во-первых, постулирование положений о праве как о сложном системном явлении социальной реальности, исторически взаимосвязанном с остальными нормативными системами и вырастающем из таких взаимодополняющих друг друга источников, как комплекс естественных прав, законодательных норм и обычного права, преломляющихся в правовом сознании; во-вторых, констатирование фракта необходимости общественного признания правовых норм как гаранта их эффективности; в-третьих, актуализация 
значения государственно-правовых институций в процессе реформирования общества. Изложенные положения, характеризующие особенности права как системного общественного френомена, без сомнения, актуальны в современной правовой теории в условиях процесса глобализации, затронувшего все сферы социума, в том числе правовую подсистему. Особую значимость они приобретают в связи с требованием построения внутренне непротиворечивой системы права с учетом усложняющихся внутригосударственных реформационных процессов и активизации участия Российского государства в международных правовых отношениях.

\section{Ссылки:}

1. Ершов В.В. Правовое и индивидуальное регулирование общественных отношений : монография. М., 2018. 627 с.

2. Holl J. Integrative Jurisprudence // Interpretations of Modern Legal Philosophies: Essays in Honor or Roscoe Pound / ed. and introd. by P. Sayre. N. Y., 1947. P. 325-332.

3. Палеха P.P., Ситникова Е.Л. Первые интегративные теории правопонимания в российской и зарубежной юридической науке // Вестник Воронежского государственного университета. Сер.: Право. 2018. № 1 (32). С. 37-47.

4. Виноградов П.Г. Очерки по теории права. Изд. 2-е. М., 2015. 152 с.

5. Сорокин П.А. Преступление и кара, подвиг и награда: социологический этюд об основных формах общественного поведения и морали. М., 2006. 612 с.

6. Сорокин П. Элементарный учебник общей теории права в связи с учением о государстве. Ярославль, 1919. 236 с.

7. Сорокин П.А. Преступление ... С. 176

8. Там же. С. $182,185$.

9. Виноградов П.Г. Указ. соч. С. 23

10. Там же. С. 24.

11. Там же. С. 151-152.

12. Там же. С. 93.

13. Ященко А.С. Теория федерализма: опыт синтетической теории права и государства. Изд. 2-е. Т. 1. М., 2012. 408 с.

14. Там же. С. 2.

15. Гараева Г.Ф., Корнев В.Н. Особенности синтетического подхода А.С. Ященко к определению права // Общество: политика, экономика, право. 2017. № 11. С. 84-88. https://doi.org/10.24158/pep.2017.11.18.

16. Ященко А.С. Указ. соч. С. 43.

17. Там же. С. 45 .

18. Там же. С. 91-92.

19. Там же. С. 104

20. Гусарова М.А. Концепции правосознания в философско-правовой мысли России (на примере взглядов П.И. Новгородцева, И.А. Ильина и Л.И. Петражицкого) // Общество: политика, экономика, право. 2013. № 2. С. 73-79.

21. Ященко А.С. Указ. соч. С. 111.

22. Там же. С. 108

23. Там же. С. 181

24. Жуков В.Н. Русская философия права: от рационализма к мистицизму : монография. М., 2017. 351 с.

\section{References:}

Ershov, VV 2018, Legal and Individual Regulation of Social Relations: a Monograph, Moscow, 627 p., (in Russian).

Garaeva, GF \& Kornev, VN 2017, 'Features of A.S. Yashchenko's Synthetic Approach to Law', Obshchestvo: politika, ekonomika, pravo, no. 11, pp. 84-88, https://doi.org/10.24158/pep.2017.11.18, (in Russian).

Gusarova, MA 2013, 'Conceptions of Legal Awareness in the Legal Philosophy Ideas of Russia (Case Study of P.I. Novgorodtsev's, I.A. Ilyin's and L.I. Petrazhitskiy's Views', Obshchestvo: politika, ekonomika, pravo, no. 2, pp. 73-79, (in Russian).

Holl, J 1947, 'Integrative Jurisprudence', in P Sayre (ed. and introd.), Interpretations of Modern Legal Philosophies: Essays in Honor or Roscoe Pound, New York, pp. 325-332.

Palekha, RR \& Sitnikova, EL 2018, 'The First Theories of Integrative Law in Russian and Foreign Science of Law', Vestnik Voronezhskogo gosudarstvennogo universiteta. Ser.: Pravo, no. 1 (32), pp. 37-47, (in Russian).

Sorokin, P 1919, Elementary Textbook of General Theory of Law in Connection with the Doctrine of the State, Yaroslavl, 236 p., (in Russian).

Sorokin, PA 2006, Crime and Punishment, Feat and Reward: Sociological Etude on the Main Forms of Social Behavior and Morality, Moscow, 612 p., (in Russian).

Vinogradov, PG 2015, Essays on the Theory of Law, $2^{\text {nd }}$ ed., Moscow, 152 p., (in Russian).

Yashchenko, AS 2012, The Theory of Federalism: Experience of Synthetic Theory of Law and State, $2^{\text {nd }}$ ed., vol. 1, Moscow, 408 p., (in Russian).

Zhukov, VN 2017, Russian Philosophy of Law: from Rationalism to Mysticism: a Monograph, Moscow, 351 p., (in Russian). 